Research Article

\title{
A Mathematical Model to Simulate Static Characteristics of T-Beam Bridge with Wide Flange
}

\author{
Xiaomeng Zang, ${ }^{1}$ Genhui Wang, ${ }^{1}$ Jianchang $\mathrm{Li}^{2}{ }^{2}$ Rongcheng Hou, ${ }^{3}$ Yanan Gan $\mathbb{D}^{4},{ }^{4}$ \\ Junjie Wang, and Wei Zhang $^{3}$ \\ ${ }^{1}$ School of Civil Engineering, Lanzhou Jiaotong University, Lanzhou, Gansu 730070, China \\ ${ }^{2}$ Department of Mathematical Science, Xi'an Jiaotong-Liverpool University, Suzhou, Jiangsu 215000, China \\ ${ }^{3}$ School of Civil Engineering, Anhui Jianzhu University, Hefei, Anhui 230601, China \\ ${ }^{4}$ School of Civil Engineering, Yancheng Institute of Technology, Yancheng, Jiangsu 224051, China \\ ${ }^{5}$ School of Economics and Management, Anhui Jianzhu University, Hefei, Anhui 230601, China \\ Correspondence should be addressed to Yanan Gan; gyn-12@163.com
}

Received 21 November 2020; Revised 15 December 2020; Accepted 8 January 2021; Published 30 January 2021

Academic Editor: Hijaz Ahmad

Copyright (c) 2021 Xiaomeng Zang et al. This is an open access article distributed under the Creative Commons Attribution License, which permits unrestricted use, distribution, and reproduction in any medium, provided the original work is properly cited.

\begin{abstract}
This study considers various factors, such as shear lag effect and shear deformation, and introduces the self-stress equilibrium for shear lag warping stress conditions to analyze the static characteristics of T-beam bridges accurately. In the mechanical analysis, three generalized displacement functions are applied, and the governing differential equations and natural boundary conditions of the static characteristics of T-beams are established on the basis of the energy variational principle. In the example, the influences of the shear lag effect, different load forms, and span ratio on the mechanical properties of T-beam bridges are analyzed. Therefore, the method of this study enriches and develops the theoretical analysis of T-beams, and it plays a certain guiding role in designing such a structure.
\end{abstract}

\section{Introduction}

Reinforced concrete T-beam bridges were widely used in the 1970s and 1980s because of their simple force and convenient design and construction [1-5]. In recent years, fabricated concrete $\mathrm{T}$-beam bridges have been widely utilized in the construction of expressways and railways in China, such as the approach bridge of Qingshan Yangtze River Highway Bridge in Wuhan and the bridge of Chongqing Chengkai Expressway. However, with the increase in highway and railway traffic, such structures can be seriously damaged, such as cracks on the flange and web, which reduce their overall stiffness and further deteriorate their mechanical properties [6-9]. For example, in 773 overpasses and river crossing bridges in Beijing, most $\mathrm{T}$-beam bridges have cracks, water seepage corrosion, and concrete spalling. Therefore, the refined mechanical analysis of T-beam bridges has theoretical and engineering significance.
Currently, scholars have conducted intensive research on T-beam bridges, but structural diseases remain serious, which shows that bridge workers still lack understanding of the mechanical properties of the T-beam bridge. New mechanical conditions should be considered when studying the mechanical properties of such structures [10-15]. Referring to the existing references, it is found that the shear lag warpage stress, moment self-balance condition, and Timoshenko shear deformation are not considered simultaneously in the analysis of mechanical properties of this kind of structure, which leads to the limitation of the calculation results. Therefore, in the present study, various factors, such as shear lag warping self-stress equilibrium, shear lag, and shear deformation, are considered comprehensively [16-20]. The governing differential equations and natural boundary conditions of the T-beam bridge are established via the energy variational method. The effects of shear lag, span ratio, and boundary conditions on mechanical properties are 
analyzed using examples. According to the current external environmental conditions and bridge disease characteristics, the method adopted in this paper is to enrich and develop the existing theory of thin-walled structure analysis [21-24] and has certain guiding significance for such structural design.

\section{Control Differential Equation and Natural Boundary Conditions of T-Beam Bridge}

2.1. Setting of the Longitudinal Warping Displacement Function of T-Beam Flange. The force system shown in Figure 1 acts on the T-beam shown in Figure 2. If the structure span is $L$, then the symmetrical bending state $w(z), \theta(z)$ represents the vertical deflection and vertical angle of the T-beam section of elementary beam theory, respectively, and $v_{j}(z)$ is the vertical deflection caused by the shear lag effect of the T-beam. Then, the longitudinal displacement of the T-beam flange $u_{z}$ is the sum of the theoretical value of the elementary beam and the longitudinal hysteresis displacement of the wing caused by the shear hysteresis effect.

The longitudinal displacement of the T-beam flange plate is as follows:

$$
u_{z}(x, y, z)=y \theta+[y-\alpha \varphi(x)-\beta] v_{j}^{\prime},
$$

where $\varphi(x)=1-\left(\left(x-\left(t_{w} / 2\right)\right)^{2} / b^{2}\right)$ is the nonuniform distribution function of the T-beam flange and $\alpha$ and $\beta$ are correction coefficients of the flange satisfying the self-stress equilibrium for the shear lag warping stress. Among them, $\left(t_{w} / 2\right) \leq x \leq\left(b+\left(t_{w} / 2\right)\right)$.
Then, the shear lag stress of the T-beam flange is as follows:

$$
\sigma_{Y B}=E[y-\alpha \varphi(x)] v_{j}^{\prime \prime}-E \beta v_{j}^{\prime \prime},
$$

where $\alpha, \beta$ are the constant coefficients obtained to satisfy $\int_{A} \sigma_{Y B} \mathrm{~d} A=0 \quad$ and $\quad \int_{A} \sigma_{Y B} y \mathrm{~d} A=0: \quad \alpha=\left(3 I / 4 h_{1} b t\right), \beta=$ The longitudinal displacement of the T-beam web is as follows:

$$
u_{f}(x, y, z)=y \theta+(y-\beta) v_{j}^{\prime}
$$

The shear stress of the T-beam flange is used as an independent stress system that satisfies the self-stress equilibrium for the shear lag warping stress. In other words, the T-shaped section will simultaneously satisfy the balance of shear lag and warpage self-stress and the bending moment.

2.2. Total Potential Energy of a T-Beam Bridge. The normal and shear stresses of the T-beam flange are expressed as

$$
\begin{aligned}
\sigma_{Z Y} & =E y \theta^{\prime}+E[y-\alpha \varphi] v_{j}^{\prime \prime}-E \beta v_{j}^{\prime \prime}, \\
\tau_{j} & =G \frac{\partial u_{z}}{\partial x}=-G \alpha \frac{\partial \varphi}{\partial x} v_{j}^{\prime} .
\end{aligned}
$$

The normal stress of the T-beam web is obtained as

$$
\sigma_{Z F}=E y \theta^{\prime}+E(y-\beta) v_{j}^{\prime \prime} .
$$

The deformation potential energy of T-beam bridges is calculated as follows:

The strain energies of the flange and web are obtained as

$$
U_{z 1}=\frac{1}{2} \iint\left(\frac{\sigma_{Z Y}^{2}}{E}+\frac{\tau_{j}^{2}}{G}+\frac{\sigma_{Z F}^{2}}{E}\right) \mathrm{d} A \mathrm{~d} z=\frac{1}{2} \int_{0}^{l} E I\left(\theta^{\prime}\right)^{2} \mathrm{~d} z+\frac{1}{2} \int_{0}^{l} 2 E I_{1} \theta^{\prime} v_{j}^{\prime \prime} \mathrm{d} z+\frac{1}{2} \int_{0}^{l} E I_{2}\left(v_{j}^{\prime \prime}\right)^{2} \mathrm{~d} z+\frac{1}{2} \int_{0}^{l} G I_{G}\left(v_{j}^{\prime}\right)^{2} \mathrm{~d} z
$$

where $\quad I=\int_{A_{1}} y^{2} \mathrm{~d}_{A_{1}}+\int_{A_{f}} y^{2} \mathrm{~d}_{A_{f}} ; I_{1}=0 ; I_{2}=I+\beta^{2} A+$ $(16 / 15) \alpha^{2} b t_{1}+(8 / 3) \alpha b t_{1}\left(\beta-h_{1}\right) ; I_{G}=\left(8 \alpha^{2} t_{1} / 3 b\right)$.

Timoshenko's shear strain energy is expressed as

$$
U_{G}=\frac{1}{2} \int_{0}^{l} k G A\left(w^{\prime}-\theta\right)^{2} \mathrm{~d} z
$$

The load potential energy is measured as

$$
U_{p}=-\int_{0}^{l} q_{y}\left(w+v_{j}\right) \mathrm{d} z-\left.Q\left(w+v_{j}\right)\right|_{0} ^{l}-\left.\left(M_{1} v_{j}^{\prime}+M_{z} \theta\right)\right|_{0} ^{l}
$$

Then, the total potential of the system is as follows:

$$
U=U_{z 1}+U_{G}+U_{p}
$$

where $M_{1}(z)$ is the bending moment of the $x$-axis generated by the shear lag effect of the T-beam flange; $M_{z}(z)$ is the bending moment of the $x$-axis when the beam end produces a vertical corner of $\theta(z) ; Q(z), q_{y}(z)$ are the vertical shear force at the beam end and the vertical distribution force on the T-beam, respectively; $E, G$ are Young's and shear moduli of the T-beam material, respectively; $A_{1}, A_{f}$ are the crosssectional areas of the T-beam flange and web, respectively, in which $A=A_{1}+A_{f}$; and $I$ is the moment of inertia of the T-beam of the $x$-axis.

2.3. Control Differential Equations and Natural Boundary Conditions of T-Beams. On the basis of the variational principle, the governing differential equation of the T-beam can be derived as

$$
\begin{gathered}
E I \theta^{\prime \prime}+k G A\left(w^{\prime}-\theta\right)=0, \\
k G A\left(w^{\prime \prime}-\theta^{\prime}\right)+q_{y}=0, \\
E I_{2} v_{j}^{(4)}-G I_{G} v_{j}^{\prime \prime}-q_{y}=0 .
\end{gathered}
$$




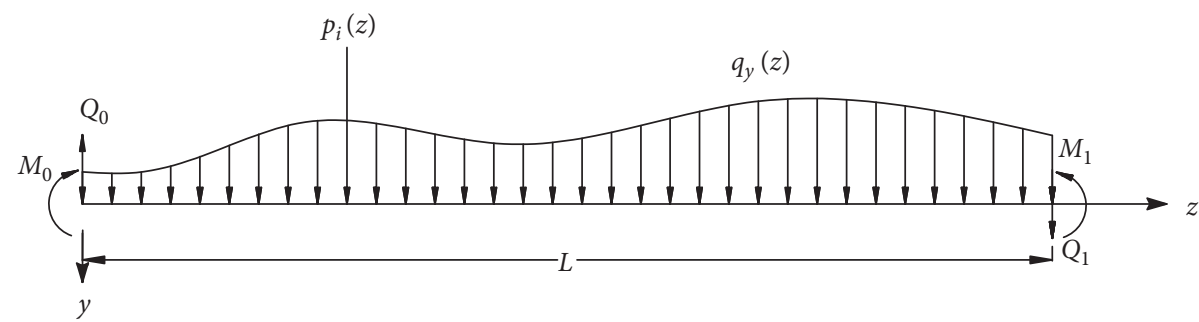

Figure 1: Coordinate and load system.

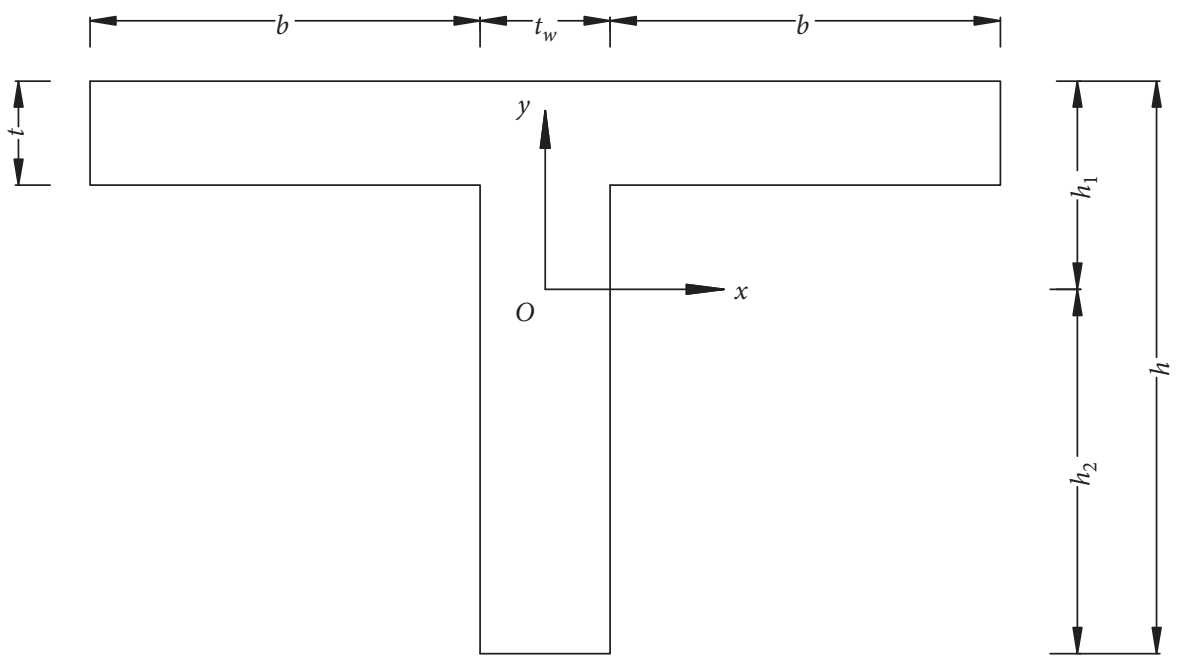

Figure 2: Cross section of T-beams.

The natural boundary conditions are as follows:

$$
\begin{array}{r}
{\left.\left[E I \theta^{\prime}-M_{z}\right]\right|_{0} ^{l} \delta \theta=0,} \\
{\left.\left[k G A\left(w^{\prime}-\theta\right)-Q\right]\right|_{0} ^{l} \delta w=0,} \\
{\left.\left[E I_{2} v_{j}^{\prime \prime}-M_{1}\right]\right|_{0} ^{l} \delta v_{j}^{\prime}=0,} \\
{\left.\left[E I_{2} v_{j}^{(3)}+G I_{G} v_{j}^{\prime}-Q\right]\right|_{0} ^{l} \delta v_{j}=0 .}
\end{array}
$$

By substituting differential equations (10) and (11), $w(z)$ and $\theta(z)$ are calculated as

$$
\begin{aligned}
& w(z)=c_{1} z^{3}+c_{2} z^{2}+c_{3} z+c_{4}+\frac{q_{y}}{24 E I} z^{4}, \\
& \theta(z)=c_{1}\left(3 z^{2}+\frac{6 E I}{k G A}\right)+c_{2} 2 z+c_{3}+\frac{q_{y}}{k G A} z+\frac{q_{y}}{6 E I} z^{3},
\end{aligned}
$$

where $c_{1}, c_{2}, c_{3}$, and $c_{4}$ are the constant coefficients obtained in accordance with the corresponding boundary conditions of $w(z)$ and $\theta(z)$.

Similarly, by substituting differential equation (12),

$$
v_{j}^{(4)}+\frac{-G I_{G}}{E I_{2}} v_{j}^{\prime \prime}+\frac{-1}{E I_{2}} q_{y}=0 .
$$

The solution of its characteristic equation is $r_{1,2}= \pm \eta$.
Therefore, differential equation (18) is calculated as

$$
v_{j}(z)=s_{1} \operatorname{ch}(\eta z)+s_{2} \operatorname{sh}(\eta z)+s_{3} z+s_{4}+\frac{-q_{y}}{2 G I_{G}} z^{2},
$$

where $s_{1}, s_{2}, s_{3}$, and $s_{4}$ are the constant coefficients obtained in accordance with the corresponding boundary conditions of $v_{j}(z)$.

On the basis of differential equations (10)-(12), the T-beam mechanical properties are composed of two independent mechanical systems, namely, the superposition of elementary beam theory and the shear lag theory system.

\section{Natural Boundary Conditions Commonly Used for T-Beams}

The specific boundary conditions of elementary beam theory can be obtained using equations (13) and (14). The commonly used boundary conditions are as follows.

3.1. Boundary Conditions for $w(z)$ and $\theta(z)$

(1) Uniform load:

$$
\begin{aligned}
& \left.w(z)\right|_{0} ^{l}=0 ; \\
& \left.\theta^{\prime}(z)\right|_{0} ^{l}=0 .
\end{aligned}
$$

(2) Concentrated load: 
For a simple-supported T-beam, if the force applied between the spans includes one or more concentrated forces (Figure 3) and the distances between adjacent forces of the concentrated force $P_{k}$ are $L_{k 1}$ and $L_{k 2}$, the subscripts of $w(z)$ and $\theta(z)$ represent $z_{1}$ or $z_{2}$ coordinates. Therefore, the following continuous boundary conditions should be introduced at the k-point:

$$
\begin{aligned}
w_{1}\left(L_{k 1}\right) & =w_{2}(0), \\
w_{1}^{\prime}\left(L_{k 1}\right) & =w_{2}^{\prime}(0), \\
\theta_{1}^{\prime}\left(L_{k 1}\right) & =\theta_{2}^{\prime}(0), \\
\theta_{1}\left(L_{k 1}\right)-\theta_{1}(0) & =\frac{P_{k}}{k G A} .
\end{aligned}
$$

Similarly, the boundary conditions of shear lag theory can be obtained using equations (15) and (16). The commonly used boundary conditions are as follows.

\subsection{Boundary Conditions for $v_{j}(z)$}

(1) Uniform force:

$$
\begin{aligned}
\left.v_{j}(z)\right|_{0} ^{l} & =0 ; \\
\left.v_{j}^{\prime \prime}(z)\right|_{0} ^{l} & =0 .
\end{aligned}
$$

\section{(2) Concentrated force:}

If the force applied between the spans includes one or more concentrated forces (Figure 3 ) and the subscript number of $v_{j}$ indicates whether it is in the $z_{1}$ or $z_{2}$ coordinate system, then the $k$-point should also introduce the boundary conditions as

$$
\begin{aligned}
v_{j 1}(0) & =0, \\
v_{j 1}\left(L_{k 1}\right) & =v_{j 2}(0), \\
v_{j 1}^{\prime}\left(L_{k 1}\right) & =v_{j 2}^{\prime}(0), \\
v_{j 1}^{\prime \prime}\left(L_{k 1}\right) & =v_{j 2}^{\prime \prime}(0), \\
v_{j 2}\left(L_{k 2}\right) & =0, \\
v_{j 1}^{\prime \prime}(0) & =0, \\
v_{j 2}^{\prime \prime}\left(L_{k 2}\right) & =0, \\
v_{j 1}^{(3)}\left(L_{k 1}\right)-v_{j 2}^{(3)}(0) & =\frac{-P_{k}}{\left(E I_{2}\right)} .
\end{aligned}
$$

\section{Analysis of the Example of T-Beam Bridge}

The material and geometric parameters for C50 reinforced concrete T-beam are as follows: elastic modulus
$E=3.5 \times 10^{4} \mathrm{MPa}$, shear modulus $G=1.5 \times 10^{4} \mathrm{MPa}$, thickness of web $t_{w}=0.2 \mathrm{~m}$, thickness of wing plate $t=0.1 \mathrm{~m}$, length of wing plate $b=2.4 \mathrm{~m}$, and T-beam height $h=1.2 \mathrm{~m}$. In the mechanical analysis, the uniform force $q_{y}(z)=9800(\mathrm{~N} / \mathrm{m})$ and the concentrated force $P_{k}(z)=L \times 9800 \mathrm{~N}$, where $L$ represents the simply supported beam spans or the sum of continuous beam spans. The concentrated force is applied to the simply supported beam midspan or the midspan of one of the continuous beams (Figure 4). Furthermore, the stress of the T-beam flange and the longitudinal deflection of the T-beam are calculated using the derivation formula in this study and other algorithms (note: in the calculation of ANSYS finite element method, the T-beam section is drawn in accordance with the intersection coordinates of the T-beam in Figure 2; then, the extrude function of ANSYS finite element is used to form the body; after dividing the cell grid, the simple or continuous boundary conditions are simulated to impose the corresponding constraints on the positions of T-beams for forming simple or continuous boundary conditions).

Tables 1 and 2 and Figure 5 illustrate the following:

(1) For the simply supported T-beam bridge, the effect of the concentrated load is greater than that of uniform load under the same span, and the smaller the span width ratio, the stronger the shear lag effect. The shear lag effect of continuous T-beam bridges is more prominent than that of simply supported T-beam bridges. Moreover, the shear lag effect of continuous T-beam bridges with uniform load is greater than that with concentrated loads. Therefore, bridge experts should pay attention to this aspect.

(2) With the introduction of self-stress equilibrium for the shear lag warping stress, the mechanical properties of T-beams are decomposed into independent elementary beam theory and shear lag theory system, which is the innovation of this study. The example further shows that the mechanical properties of T-beam bridges are superimposed by the theoretical values of the elementary beam and the calculated values of shear lag theory.

Tables 3 and 4 and Figure 6 illustrate the following:

(1) The normal stress of the T-beam web is composed of two parts, namely, the sum of the theoretical value of the elementary beam and the influence of the shear lag effect. As the shear lag effect increases, its influence on the normal stress of the web increases.

(2) Existing research suggests that the normal stress of the T-beam web is only affected by elementary beam theory. The influence of the shear lag effect on the normal stress of the web cannot be ignored. As shown in Table 3, the shear lag effect increases the compressive stress of the simply supported T-shaped web by $33.34 \%$. In Table 4 , the shear lag effect increases the tensile stress of the continuous T-shaped web by $42.57 \%$. Ignoring the impact will likely cause structural damage; thus, this feature 


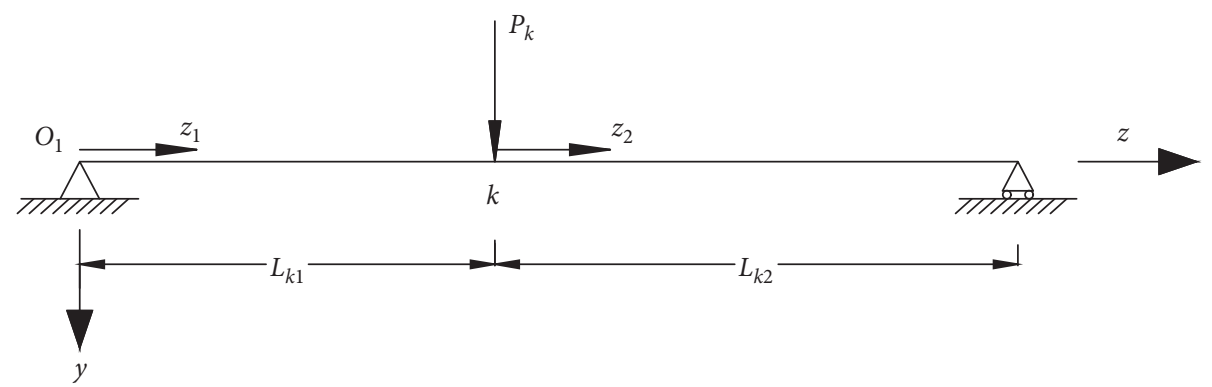

Figure 3: Coordinate and load system of T-beams.

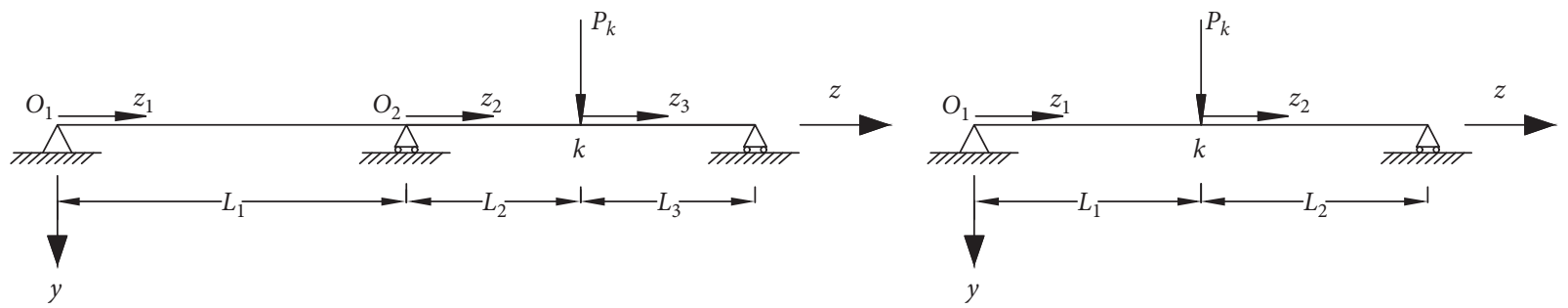

(a)

(b)

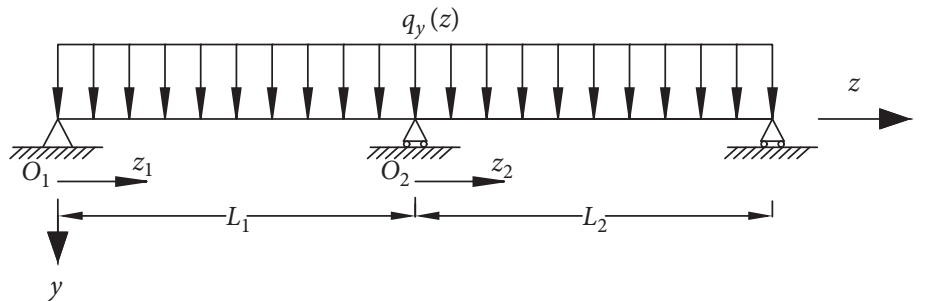

(c)

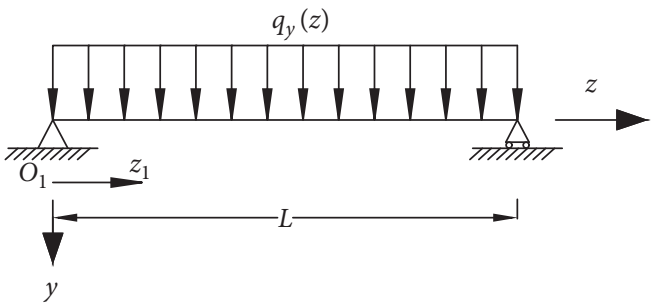

(d)

FIGURE 4: Boundary conditions and load systems for the mechanical analysis of T-beams: (a) two-span continuous T-beam with concentrated load; (b) simply supported T-beam with concentrated load; (c) two-span continuous T-beam with uniform load; (d) simply supported T-beam with uniform load.

TABle 1: Stress of the flange for two-span continuous T-beams $\left(L_{1}=L_{2}=12 \mathrm{~m}\right)$ (uniform load).

\begin{tabular}{|c|c|c|c|c|c|c|c|}
\hline Horizontal coordinate of flange $(\mathrm{m})$ & 0 & 0.4 & 0.8 & 1.2 & 1.6 & 2.0 & 2.4 \\
\hline Elementary beam theoretical value $\left(10^{4} \mathrm{pa}\right)$ & 42.726 & 42.726 & 42.726 & 42.726 & 42.726 & 42.726 & 42.726 \\
\hline Shear lag effect value $\left(10^{4} \mathrm{pa}\right)$ & -28.565 & -26.381 & -19.978 & -9.792 & 3.482 & 18.941 & 35.529 \\
\hline Total stress value $\left(10^{4} \mathrm{pa}\right)$ & 14.161 & 16.345 & 22.748 & 32.934 & 46.208 & 61.667 & 78.255 \\
\hline Finite element value $\left(10^{4} \mathrm{pa}\right)$ & 13.657 & 15.579 & 21.691 & 31.287 & 43.945 & 58.798 & 74.882 \\
\hline Shear lag coefficient & 0.33 & 0.38 & 0.53 & 0.77 & 1.08 & 1.44 & 1.83 \\
\hline
\end{tabular}

Note: the uniform load calculation section is the fulcrum.

TABLE 2: Stress of the flange for two-span continuous T-beams $\left(L_{1}=12 \mathrm{~m} ; L_{2}=L_{3}=6 \mathrm{~m}\right)$ (concentrated load).

\begin{tabular}{lccccccc}
\hline Horizontal coordinate of flange $(\mathrm{m})$ & 0 & 0.4 & 0.8 & 1.2 & 1.6 & 2.0 & 2.4 \\
\hline Elementary beam theoretical value $\left(10^{4} \mathrm{pa}\right)$ & 59.683 & 59.683 & 59.683 & 59.683 & 59.683 & 59.683 & 59.683 \\
Shear lag effect value $\left(10^{4} \mathrm{pa}\right)$ & -35.569 & -32.850 & -24.877 & -12.193 & 4.336 & 23.585 & 44.241 \\
Total stress value $\left(10^{4} \mathrm{pa}\right)$ & 24.114 & 26.833 & 34.806 & 47.491 & 64.019 & 83.268 & 103.924 \\
Finite element value $\left(10^{4} \mathrm{pa}\right)$ & 22.842 & 25.515 & 33.047 & 45.174 & 61.123 & 79.354 & 99.317 \\
Shear lag coefficient & 0.40 & 0.45 & 0.58 & 0.80 & 1.07 & 1.40 & 1.74 \\
\hline
\end{tabular}

Note: the calculated section is the fulcrum. 


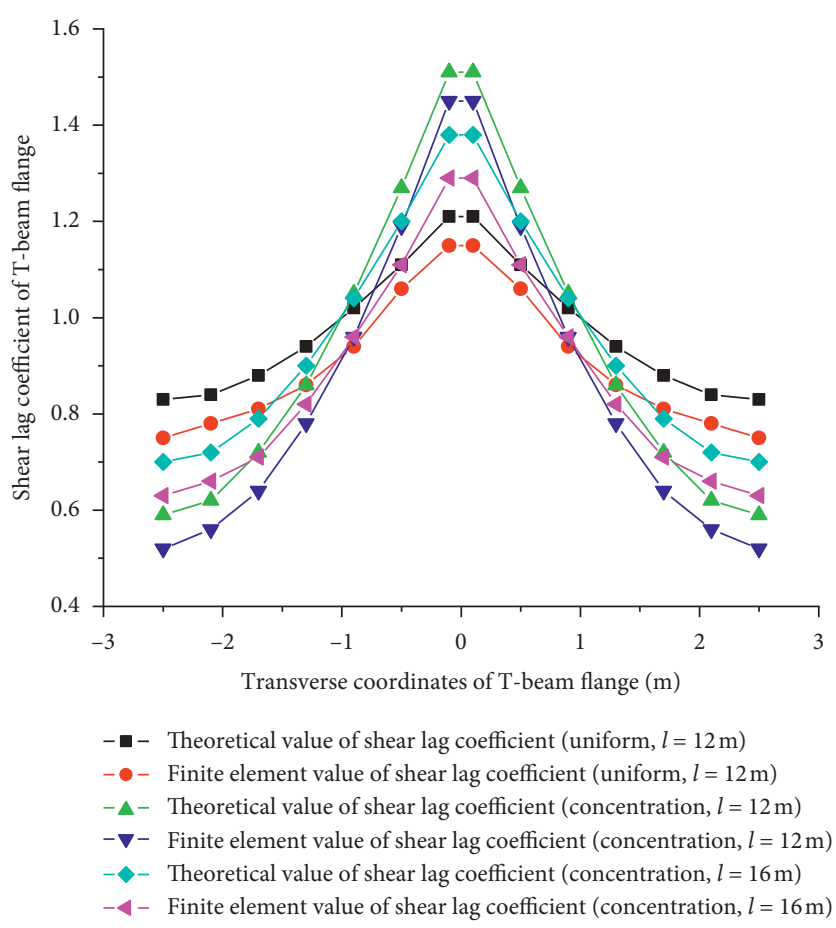

FIGURE 5: Shear lag coefficients for simply supported T-beams.

TABLE 3: Stress on webs for simply supported T-beams $\left(L_{1}=L_{2}=6 \mathrm{~m}\right)$ (concentrated load).

\begin{tabular}{|c|c|c|c|c|c|c|c|c|}
\hline Vertical coordinates of web $(\mathrm{m})$ & 0.2 & 0.1 & 0 & -0.2 & -0.4 & -0.6 & -0.8 & -1 \\
\hline Elementary beam theoretical value $\left(10^{5} \mathrm{pa}\right)$ & -8.082 & -4.041 & 0 & 8.082 & 16.165 & 24.247 & 32.329 & 40.412 \\
\hline Shear lag effect value $\left(10^{5} \mathrm{pa}\right)$ & -4.043 & -3.542 & -3.041 & -2.040 & -1.038 & -0.037 & 0.965 & 1.966 \\
\hline Total stress value $\left(10^{5} \mathrm{pa}\right)$ & -12.125 & -7.583 & -3.041 & 6.042 & 15.127 & 24.210 & 33.294 & 42.378 \\
\hline Finite element value $\left(10^{5} \mathrm{pa}\right)$ & -11.434 & -7.217 & -2.862 & 5.748 & 14.345 & 23.048 & 31.396 & 39.895 \\
\hline Effect of shear lag effect (\%) & 33.34 & 46.71 & 100 & -33.75 & -6.86 & -0.15 & 2.90 & 4.64 \\
\hline
\end{tabular}

TAвLe 4: Stress on webs for two-span continuous T-beams $\left(L_{1}=12 \mathrm{~m} ; L_{2}=L_{3}=6 \mathrm{~m}\right)$ (concentrated load).

\begin{tabular}{lcccccccc}
\hline Vertical coordinates of web $(\mathrm{m})$ & 0.2 & 0.1 & 0 & -0.2 & -0.4 & -0.6 & -0.8 & -1 \\
\hline Elementary beam theoretical value $\left(10^{5} \mathrm{pa}\right)$ & 5.968 & 3.031 & 0 & -5.968 & -12.124 & -18.185 & -24.247 & -30.309 \\
Shear lag effect value $\left(10^{5} \mathrm{pa}\right)$ & 4.424 & 3.891 & 3.341 & 2.241 & 1.140 & 0.040 & -1.060 & -2.160 \\
Total stress value $\left(10^{5} \mathrm{pa}\right)$ & 10.392 & 6.922 & 3.341 & -3.727 & -10.984 & -18.145 & -25.307 & -32.469 \\
Finite element value $\left(10^{5} \mathrm{pa}\right)$ & 9.799 & 6.457 & 3.143 & -3.485 & -10.297 & -17.058 & -23.614 & -30.491 \\
Effect of shear lag effect $(\%)$ & 42.57 & 56.21 & 100 & -60.13 & -10.38 & -0.22 & 4.19 & 6.65 \\
\hline
\end{tabular}

Note: the calculated section is the fulcrum.

should be of great concern to the architect of the structure.

(3) A stress acts on the neutral axis of T-beam bridge elementary beam theory due to the shear lag effect. As shown in Table 4, the stress value is $3.341 \times 10^{5} \mathrm{pa}$. Hence, the neutral axis is not a neutral axis in the actual sense. The axis moves down.

Table 5 and Figure 7 illustrate the following:
(1) The vertical deflection of the T-beam bridge increases due to the influence of shear lag effect. Thus, the shear lag effect reduces the vertical stiffness of the T-beam bridge. Therefore, this study has theoretical and engineering practical significance.

(2) Similarly, the vertical deflection of the T-beam bridge is still the superposition of the theoretical value of the elementary beam and the influence of the 


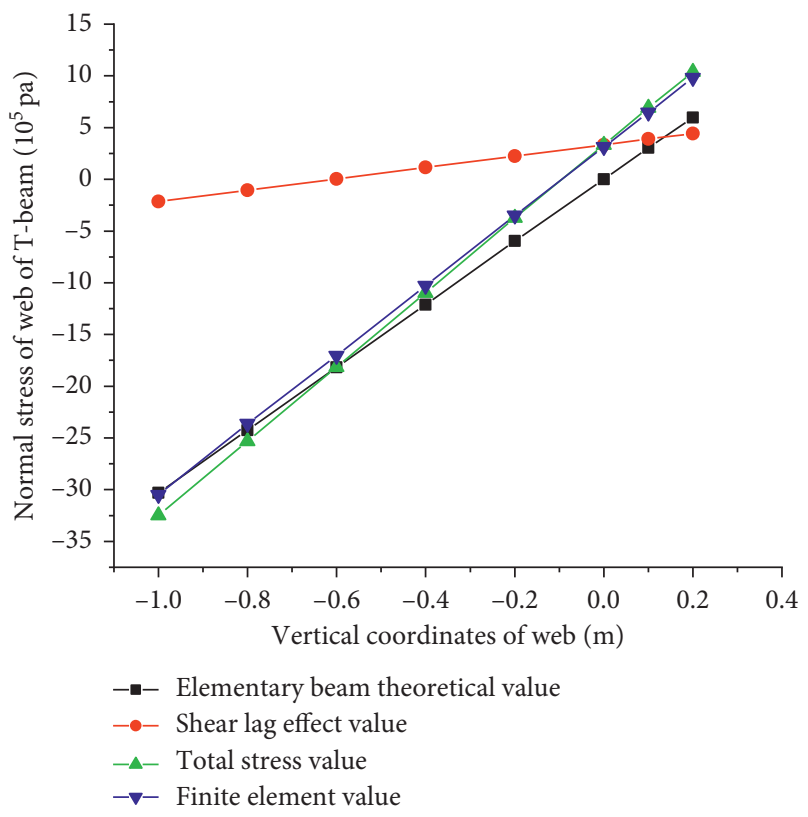

Figure 6: Stress on T-beam webs near the bridge bearing for continuous T-beams $\left(L_{1}=12 \mathrm{~m}, L_{2}=L_{3}=6 \mathrm{~m}\right.$, concentrated load $)$.

Table 5: Deflection for simply supported T-beams $(z=(L / 2), L=12 \mathrm{~m})$ (uniform load).

\begin{tabular}{|c|c|c|c|c|c|c|c|}
\hline Longitudinal coordinates of T-beam $(\mathrm{m})$ & 0 & 1 & 2 & 3 & 4 & 5 & 6 \\
\hline Elementary beam theoretical value $\left(10^{-5} \mathrm{~m}\right)$ & 0 & 24.347 & 46.673 & 65.535 & 79.809 & 88.694 & 91.710 \\
\hline Shear lag effect value $\left(10^{-5} \mathrm{~m}\right)$ & 0 & 1.396 & 2.635 & 3.638 & 4.368 & 4.811 & 4.959 \\
\hline Total deflection value $\left(10^{-5} \mathrm{~m}\right)$ & 0 & 25.743 & 49.308 & 69.173 & 84.177 & 93.505 & 96.669 \\
\hline Finite element value $\left(10^{-5} \mathrm{~m}\right)$ & 0 & 24.271 & 47.356 & 66.885 & 81.226 & 90.579 & 93.716 \\
\hline Effect of shear lag effect (\%) & 0 & 5.42 & 5.34 & 5.26 & 5.19 & 5.15 & 5.13 \\
\hline
\end{tabular}

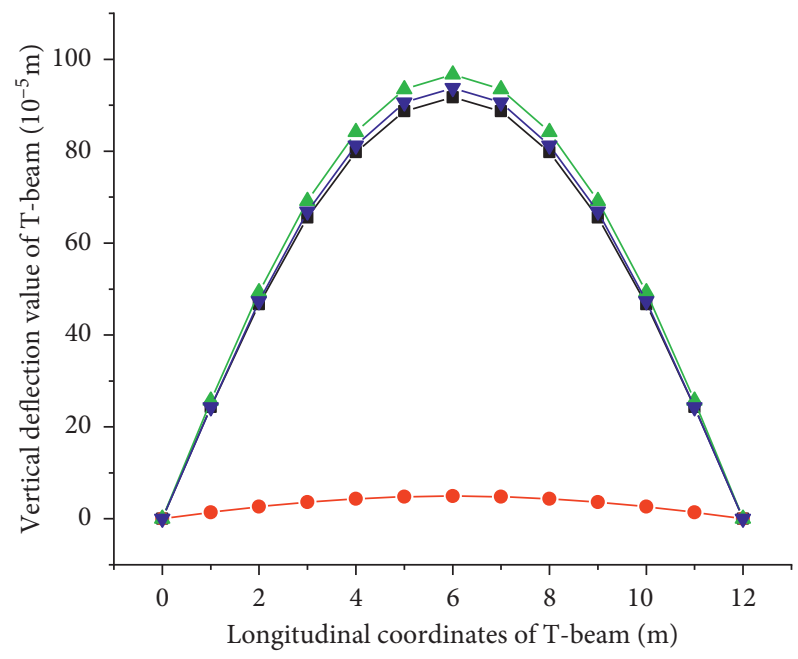

- Elementary beam theoretical value

- - Shear lag effect value

- $\_$- Total deflection value

$-\nabla$ - Finite element value

Figure 7: Deflections for simply supported T-beams ( $L=12 \mathrm{~m}$, uniform load). 
shear lag effect, and no coupling relationship exists between the two.

\section{Conclusion}

The mechanical concept of this method is clear, and the theoretical foundation is reliable due to the introduction of the self-stress equilibrium for the shear lag warping stress. The method provides a great guiding role for designing simply supported beam or continuous T-beam bridges. In particular, the mechanical properties of the web of T-beam bridges are analyzed using the method of this study. The results show that the webs of such structure are affected by the shear lag effect, which is the main innovation of this research.

The method in this paper has certain theoretical significance and engineering practical value. Therefore, it is hoped that the scholars can consider the new mechanical conditions in this paper and improve the calculation accuracy when they design or study the mechanical properties of T-beam bridge in the future.

\section{Data Availability}

All data generated or used during the study appear in the submitted article.

\section{Conflicts of Interest}

The authors declare that they have no conflicts of interest.

\section{Acknowledgments}

The authors are grateful to Dr. Baoquan Cheng for his technical support. Innovative Research Group Project of the National Natural Science Foundation of China (51878323) and Youth Science Foundation of Lanzhou Jiaotong University (2018037) supported this study.

\section{References}

[1] R. B. Abdul-Ahad and O. Q. Aziz, "Flexural strength of reinforced concrete T-beams with steel fibers," Cement and Concrete Composites, vol. 21, no. 4, pp. 263-268, 1999.

[2] M. F. M. Fahmy, Z. E. Abd-ElShafy, E. Zainab, Z. S. Wu, and W. Zhishen, "Experimental and numerical evaluation of the shear behavior of reinforced concrete T-beams with hybrid steel-FRP stirrups," Journal of Compo-Sites for Construction, vol. 21, no. 4, 2017.

[3] Z. Zhong-Yi, C. Wan-Lin, D. Hong-Ying, and T. Gao, "Flexural performance of high strength RAC T-shape beam," Journal of BEIJING University of technology, vol. 41, no. 6, pp. 866-872, 2015.

[4] G. Zhang, C.-J. Wang, X. Ji-ming, and H. E. Shuan-Hai, "Study of solid shear lag ratios of concrete T-girder bridge with its multiple girder ribs exposed to fire," Bridge Construction, vol. 44, no. 5, pp. 75-80, 2014.

[5] Y.-N. Gan and S. H. I. Fei-Ting, "Analysis on dynamic theory and characteristics of thin-walled T-beams with wide flanges," Journal of Dynamics and Control, vol. 11, no. 4, pp. 350-356, 2013.
[6] G.-S. Zhu, F.-S. Zhu, S. Guo-Hua, and M. A. Zuo-Xin, "Analysis on anti-bending load, rigidity and crack of prestressed CFRP and steel plate reinforced T-shape beam," Journal of Shenyang Jianzhu University(Natural Science), vol. 34, no. 2, pp. 210-221, 2018.

[7] Z. Ke-Wei, D. U. Chao-Wei, F.-X. Zheng, and Z. Yuan-Xun, "Load bearing capacity of existing highway RC T beam bridge based on fuzzy stochastic comprehensive evaluation," Journal of Zhengzhou University (Engineering Science), vol. 38, no. 4, pp. 88-93, 2017.

[8] L. Nobile, C. Carloni, and M. Nobile, "Strain energy density prediction of crack initiation and direction in cracked T-beams and pipes," Theoretical and Applied Fracture Mechanics, vol. 42, no. 1-3, pp. 137-145, 2001.

[9] P. Ricci and E. Viola, "Stress intensity factors for cracked T-sections and dynamic behaviour of T-beams," Engineering Fracture Mechanics, vol. 73, no. 1, pp. 91-111, 2006.

[10] M. Nakamura, T. Nakamura, and J. Niwa, "Shear resistance mechanism and shear capacity OF rc t-beams with various shear span ratio and shear reinforcement ratio," Journal of Japan Society of Civil Engineers, Ser. E2 (Materials and Concrete Structures), vol. 73, no. 3, pp. 337-347, 2017.

[11] L Qiao, C.-Q. Han, and X. Qing-Feng, "Experimental research and numerical analysis of the flexural behavior of RC continuous T-beam with high-strength bar after fire," Engineering Mechanics, vol. 32, no. 12, pp. 179-187, 2015.

[12] S. Xu-Dong, G. Ya-Ping, and Y. Ban-Fu, "Design and preliminary experiments of UHPC $\pi$-shaped girder bridge," China Journal of Highway and Transport, vol. 31, no. 1, pp. 46-56, 2018.

[13] L. I. Li-Feng, F. Xin, and S. Xu-Dong, "Experimental study on flexural behavior of large-scale prestressed UHPC T-shaped beam," China Civil Engineering Journal, vol. 51, no. 5, pp. 84-94, 2018.

[14] X.-R. Guo, H.-A. Chen, and Q.-Y. Zeng, "Dynamic characteristics analysis model of prestressed concrete T-type beam," Chinese Journal of Computational Mechanics, vol. 17, no. 2, pp. 176-183, 2000.

[15] A. J. Hull, A. J. Hull, D. Perez, and D. L. Cox, "A comprehensive analytical dynamic model of a T-beam," International Journal of Acoustics and Vibration, vol. 24, no. 1, pp. 138-149, 2019.

[16] Q.-X. Shi and B. Wang, "Simplified calculation of effective flange width for shear walls with flange," The Structural Design of Tall and Special Buildings, vol. 25, no. 12, pp. 558-577, 2016.

[17] A. Belica, "Discussion of "Formulas for shearlag effect of T, I, and box beams" by qigen song and alexander C. Scordelis (may, 1990, vol. 116, No. 5)," Journal of Structural Engineering, vol. 118, no. 4, pp. 1148-1150, 1992.

[18] D. Henriques, R. Gonçalves, and D. Camotim, "A physically non-linear GBT-based finite element for steel and steelconcrete beams including shear lag effects," Thin-Walled Structures, vol. 90, pp. 202-215, 2015.

[19] M. M. A. Kadhim, M. A. Majid, A. H. Adheem, and A. R. Jawdhari, "Nonlinear finite element modelling and parametric analysis of shear strengthening RC T-beams with NSM CFRP technique," International Journal of Civil Engineering, vol. 17, no. 8A, pp. 1295-1306, 2019.

[20] M. Vojnic-Purcar, A. Prokic, and M. Besevic, "A numerical model for laminated composite thin-walled members with openings considering shear lag effect," Engineering Structures, vol. 185, pp. 392-399, 2019.

[21] T. P. Vo and J. Lee, "Flexural-torsional behavior of thinwalled composite box beams using shear-deformable beam 
theory," Engineering Structures, vol. 30, no. 7, pp. 1958-1968, 2008.

[22] Q. G. Song and A. C. Scordelis, "Formulas for shear lag effect of T, I and box beams," Journal of Structural Engineering, vol. 116, no. 5, pp. 1306-1318, 1990.

[23] X. Wei-Chen and W. Xiao-Hui, "Experimental studies and FEM analysis of T-shape HPC beams prestressed with CFRP tendons," Journal of the china Railway Socity, vol. 29, no. 3, pp. 72-77, 2007.

[24] R. Lopez-Anido and H. V. S. GangaRao, "Warping solution for shear lag in thin-walled orthotropic composite beams," Journal of Engineering Mechanics, vol. 122, no. 5, pp. 449-457, 1996. 